\title{
Viability of Neotyphodium endophytic fungus and endophyte-infected and noninfected Lolium multiflorum seeds
}

\author{
Pedro E. Gundel, M. Alejandra Martínez-Ghersa, Lucas A. Garibaldi, and \\ Claudio M. Ghersa
}

\begin{abstract}
Neotyphodium endophyte fungi are vertically transmitted symbionts of cool-season grasses. The seed phase of the grass' life cycle appears to be critical for the persistence of the fungus. Endophyte viability decreases faster than seed viability, but little is known of the effects of this endophyte on seed viability. The endophyte could affect seed viability through changes in water content. Here, we assessed the effects of the endophyte on seed viability, the differential survival of endophyte and seed, and the effects of infection on seed water content. Viability of endophyte-infected and noninfected seeds and endophyte were evaluated over a period of 729 d under 12 controlled environmental conditions. Seed viability was reduced by the infection at high temperature and high relative humidity, but not under other conditions. Moreover, endophyte viability decreased faster than seed viability only under high humidity or high temperature. Seed water content was not affected by endophyte presence. The proportion of viable infected seeds was mainly affected by the loss in endophyte viability and secondly by the differential survival of infected and noninfected seeds. Knowledge on the relative importance of these processes is critical to understand the factors affecting the efficiency of endophyte vertical transmission and the frequency of endophyte-infected plants.
\end{abstract}

Key words: endophyte infection, seed longevity, endophyte longevity, endophyte transmission.

Résumé : Les champignons endophytes Neotyphodium sont des symbiotes des herbacées de saisons froides qui se transmettent verticalement. La phase séminale du cycle vital des herbacées semble critique pour la persistance de ce champignon. La viabilité de l'endophyte diminue plus rapidement que la viabilité de la semence, mais on connait peu de chose des effets de cet endophyte sur la viabilité des graines. L'endophyte pourrait affecter la viabilité des graines par des modifications de la teneur en eau. Les auteurs évaluent les effets de l'endophyte sur la viabilité des graines, sur la survie différentielle de l'endophyte et de la graine, ainsi que les effets de la colonisation sur la teneur en eau de la graine. Ils ont évalué la viabilité de graines colonisées ou non colonisées par l'endophyte, ainsi que celle de l'endophyte, sur une période de 729 jours sous 12 conditions environnementales contrôlées. La température et l'humidité relative élevées réduisent la viabilité de la graine, mais pas les autres conditions. De plus, la viabilité de l'endophyte diminue plus rapidement que celle de la graine, seulement sous des températures et des humidités élevées. La présence de l'endophyte n'affecte pas la teneur en eau des graines. La proportion des graines viables colonisées est surtout affectée par la perte de viabilité de l'endophyte et secondairement par la survie différentielle des graines colonisées et non colonisées. On doit connaître l'importance relative de ces processus pour comprendre les facteurs qui affectent l'efficacité de la transmission verticale de l'endophyte et la fréquence des plantes colonisées par l'endophyte.

Mots-clés : colonisation endophytique, longévité des graines, longévité de l'endophyte, transmission de l'endophyte.

[Traduit par la Rédaction]

\section{Introduction}

Many cool-season grasses are symbiotically associated with nonpathogenic systemic and endophytic fungi of the genus Neotyphodium (Clay and Schardl 2002; Faeth and Sullivan 2003). These microorganisms are solely vertically transmitted from the mother plant to the seeds (Siegel et al. 1984; Philipson and Christey 1986). This vertical transmission process can be imperfect, in part because a variable amount of the seeds produced by infected plants can remain uninfected (Holder et al. 1994; Welty et al. 1994; Hill et al. 2005; Wheatley et al. 2007). Further, endophyte viability in

Received 2 May 2008. Published on the NRC Research Press Web site at botany.nrc.ca on 12 January 2009.

P.E. Gundel, ${ }^{1}$ M.A. Martínez-Ghersa, and C.M. Ghersa. Instituto de Investigaciones Fisiológicas y Ecológicas vinculadas a la Agricultura - Consejo Nacional de Investigaciones Cientificas y Tecnológicas, Cátedra de Ecología, Facultad de Agronomía (University of Buenos Aires), Avenida San Martín 4453, Ciudad de Buenos Aires, C1417DSE, Argentina.

L.A. Garibaldi. Cátedra de Métodos Cuantitativos Aplicados, Facultad de Agronomía (University of Buenos Aires), Avenida San Martín 4453, Ciudad de Buenos Aires, C1417DSE, Argentina; Laboratorio Ecotono, Centro Regional Universitario Bariloche, Universidad Nacional del Comahue, Quintral 1250, Bariloche, Argentina.

${ }^{1}$ Corresponding author (e-mail: gundel@agro.uba.ar). 
relation to the host seed has been well documented in Festuca arundinacea and Lolium perenne (Rolston et al. 1986; Welty et al. 1987; Wheatley et al. 2007). These studies, conducted under different storage conditions, have shown that seeds remain viable for longer periods than the endophyte within the seed under certain storage conditions. Similar results have been observed in endophyte-infected Lolium multiflorum, but seed storage conditions were not controlled (Medvescigh et al. 2004). Endophyte mycelium in seeds that are prematurely harvested can lose its viability in a very short time (Hill et al. 2005). However, Hume and Barker (2005) reported that endophyte viability did not decline faster than that of seeds when buried in soil. These findings indicate that the viability of endophyte mycelium is strongly affected by environmental conditions. For this reason, some of the infected seeds lose their ability to generate endophyte-infected seedlings (Rolston et al. 1986; Welty et al. 1987; Hill et al. 2005; Wheatley et al. 2007).

Temporal changes in the frequency of endophyte-infected plants in a grass population may be affected by environmental conditions that reduce viability of endophyte mycelium and by differences in viability between infected and noninfected seeds. The effect of endophyte infection on seed survival has not been thoroughly investigated (Hume and Barker 2005). Previously, we compared the viability of infected and noninfected seed lots in three L. multiflorum populations under harsh environmental conditions (i.e., high temperature and seed water content). Endophyte infection did not affect the seed viability in two of the three populations, and a negative effect of endophyte infection was found in the third population (Gundel et al. 2007). The highest concentration of endophyte mycelium is usually found in the seeds (Siegel et al. 1984), where the endophyte hyphae occur between the seed coat and aleurone layer, in an infection layer just beneath the scutellum and the embryo (Philipson and Christey 1986; Majewska-Sawka and Nakashima 2004). Long-term seed survival depends mainly on seed water content, which depends on relative ambient humidity and temperature (Ellis and Roberts 1980; Vertucci and Ross 1990; Walters and Hill 1998; Hung et al. 2001). The lower survival observed in endophyte-infected seed lots could be related to higher water content, which may be caused by endophyte-induced changes in the ultrastructural anatomy of seeds (Gundel et al. 2007), which, at a given constant temperature, modulates seed water content reaching equilibrium with the surrounding atmospheric water vapour (Vertucci and Ross 1990; Walters and Hill 1998; Ellis and Hong 2006). The fungus might affect the water potential around the plant embryo, which depends on the environmental conditions during after-ripening storage.

In this paper, we investigated $(i)$ the effects of endophyte infection on L. multiflorum seed viability, (ii) the differential in survival of endophyte mycelium and its host seed, and (iii) the effects of endophyte infection on seed water content. Our goal was to assess the underlying mechanism by which the endophytic symbiont may affect the viability of the seeds it colonizes. Lolium multiflorum Lam. is an annual grass that has spread successfully around the temperate regions of the world, usually exhibiting asymptomatic infection by endophytes (Latch and Christensen 1982). The system model used in this work is the symbiosis between this grass and the endophyte fungus Neotyphodium occultans (Moon et al. 2000).

\section{Material and Methods}

\section{Seed material}

Mature seeds of L. multiflorum were collected in 2003 from a grassland in the Inland Pampa subregion (Carlos Casares, Argentina; $34^{\circ} 06^{\prime} \mathrm{S}, 60^{\circ} 25^{\prime} \mathrm{W}$ ). The area had been excluded from grazing and cropping activities for more than 30 years. The seed population had a Neotyphodium endophyte infection level of $95 \%$, based on 100 analysed seeds. To obtain endophyte-free seeds, half of the collected seeds were treated with triadimenol fungicide ( $\beta$-(4-chlorophenoxy)- $\alpha$-(1,1-dimethylethyl)-1 $H$-1,2,4-triazole-1-ethanol) at the recommended dose rate of $150 \mathrm{~g}$ a.i. $\mathrm{kg}^{-1}$. Although the effect of fungicide may depend on the type of product and time from the exposure, no carryover effect has been observed on the evaluated plant traits (Faeth and Sullivan 2003). Then, both seed lots (fungicide-treated and untreated) were sown during the normal growing season (autumnwinter-spring) in 2004 in the experimental field of the Faculty of Agronomy, University of Buenos Aires $\left(34^{\circ} 35^{\prime} \mathrm{S}, 58^{\circ} 35^{\prime} \mathrm{W}\right)$. Each seed lot was sown in a $1 \mathrm{~m}^{2}$ plot at a rate of 2500 seeds per $\mathrm{m}^{2}$. Before sowing, each plot was covered with a layer of $0.10 \mathrm{~m}$ of organic soil which was free of wild L. multiflorum seeds. Cross pollination among plants from both plots was allowed during flowering, to diminish any genetic differences between them. Mature seeds were hand collected from plants, and endophyte infection was assessed on 100 seeds per seed lot by light microscopy (Bacon and White 1994). Endophyte infection was $90 \%$ in the seed lot without fungicide application (hereinafter E+ biotype) and $2 \%$ in fungicidetreated seeds (hereinafter E- biotype). Harvested seeds were stored under dry conditions for 3 months until they were used in the experiment.

\section{Experimental storage conditions}

The effects of endophyte infection on seed viability were studied by comparing seed viability dynamics of E+ and Ebiotypes stored under 12 different conditions resulting from the combination of four temperatures and three different relative humidities. Changes in endophyte infection frequency were analysed by comparing endophyte viability with viability of E+ seeds under the same storage conditions.

Seeds were stored in four chambers, three of which were at constant temperatures $\left(5,20\right.$, and $\left.40{ }^{\circ} \mathrm{C}\right)$ and the remaining one at alternating temperatures $\left(15-25{ }^{\circ} \mathrm{C}, 10-14 \mathrm{~h}\right.$, respectively). Alternating temperature treatment usually has a higher impact on seed survival than the average temperature (Hung et al. 2001). Temperatures inside each chamber were set at the nominal value and controlled with a thermostat throughout the experiment. Within each chamber, three plastic boxes were used to set the relative humidity treatments. Relative humidities were generated by using saturated salt solutions that produce nominal values of $5 \%\left(\mathrm{ZnCl}_{2}\right), 43 \%$ $\left(\mathrm{K}_{2} \mathrm{CO}_{2} 1.5 \mathrm{H}_{2} \mathrm{O}\right)$, and $75 \%(\mathrm{NaCl})$ at $25{ }^{\circ} \mathrm{C}$. The humidities generated by these salts are known to be quite stable for the range of temperatures used in our experiment (Merritt et al. 2003). Each box had a volume of $1000 \mathrm{~mL}$, and one-third of 
this volume was filled with the saturated salt solution contained in four glass vials opened at the top. In each box, $2.2 \mathrm{~g}$ of seeds of each biotype were placed inside a nylon mesh bag allowing air exchange between the seeds and the surrounding atmosphere. The bags containing seeds were situated above the glass vials, and a plastic net $(0.5 \mathrm{~cm}$ mesh) prevented seeds from coming into contact with the liquid solutions. The boxes were closed air tight.

Water vapour atmosphere created by each treatment was evaluated throughout the experiment by recording seed water content on an independent L. multiflorum seed lot placed inside the boxes (Fig. 1). At each extraction time, three samples of 50 seeds were retrieved from each box. Fresh and dry mass was recorded by weighing seeds before and after they were dried in an oven at $130{ }^{\circ} \mathrm{C}$ for $1 \mathrm{~h}$. Seed water content was estimated using the following formula: $[(\mathrm{g}$ fresh mass $)-(\mathrm{g}$ dry mass $)] /(\mathrm{g}$ fresh mass $)$ and expressed as a percentage (ISTA 1996). Overall, the different humidity treatments worked well, as seed water content increased with increasing air relative humidity levels $(P<$ 0.0001; Fig. 1). Furthermore, the differences among the relative humidity treatments stabilized after the first $100 \mathrm{~d}$ of the experiment, reaching average values of seed water content of $7.52,11.50$, and 13.82 for $5 \%, 43 \%$, and $75 \%$, respectively. Increasing the temperature reduced the seed water content $(P<0.0001)$, an effect that was independent of the relative humidity (i.e., no temperature $\times$ relative humidity interaction; Fig. 1). The average values of seed water content were $11.74,10.71$, and 9.84 for 5,20 , and $40{ }^{\circ} \mathrm{C}$, respectively, and there was no difference between $20{ }^{\circ} \mathrm{C}$ continuous and $15-25{ }^{\circ} \mathrm{C}$ alternating temperatures.

\section{Seed and endophyte viability}

Seed viability was evaluated for each biotype on 14 extraction dates during $729 \mathrm{~d}$ of storage. On each extraction date, we counted the number of viable and nonviable seeds in 60 seeds for each of the 12 storage conditions (i.e., each box). Although for the statistical analysis viability scores from 60 seeds were pooled (see statistical analyses below), they were sown into three different Petri dishes (20 seeds each), to avoid unfortunate events affecting them. Seed viability was evaluated by incubating seeds under optimal conditions for germination of L. multiflorum: $15-25{ }^{\circ} \mathrm{C}, 12-$ $12 \mathrm{~h}$, respectively, under ambient light (ISTA 1996). Seeds were placed on a paper towel hydrated with $5 \mathrm{~mL}$ distilled water in plastic Petri dishes $(9 \mathrm{~cm}$ diameter), which were sealed with plastic film. Seed germination (visible radicle appearance) was recorded under laboratory light, and germinated seeds were removed, until no more germination was observed. Nongerminated seeds with soft and mouldy aspect were considered nonviable, while nongerminated firm seeds were dried and rehydrated to discriminate dormant from dead seeds. Maximum seed viability was estimated at the beginning of the experiment (day 0 of incubation).

The viability of endophyte mycelium in seeds was determined indirectly by examining the seedlings grown from the E+ seeds for endophyte infection. Young seedlings were transplanted into plastic trays (30 plugs of $4 \mathrm{~cm}$ diameter and $8 \mathrm{~cm}$ depth) filled with a mixture of potting soil $(50 \%)$, sand $(25 \%)$, and peat moss $(25 \%) v / v$, at a rate of one seedling per plug. Water was added as needed. At each time
Fig. 1. Seed water content (\%) along $729 \mathrm{~d}$ of storage for a Lolium multiflorum seed lot used as indicator of the effects of the nominal relative humidity treatments $[5 \%(\square), 43 \%(\bigcirc)$, and $75 \%(\Delta)]$ at four temperatures $\left(5,20,40\right.$, and $\left.15-25^{\circ} \mathrm{C}\right)$. Symbols are means and bars are SEs ( $n=3$, each sample comprised 50 seeds).

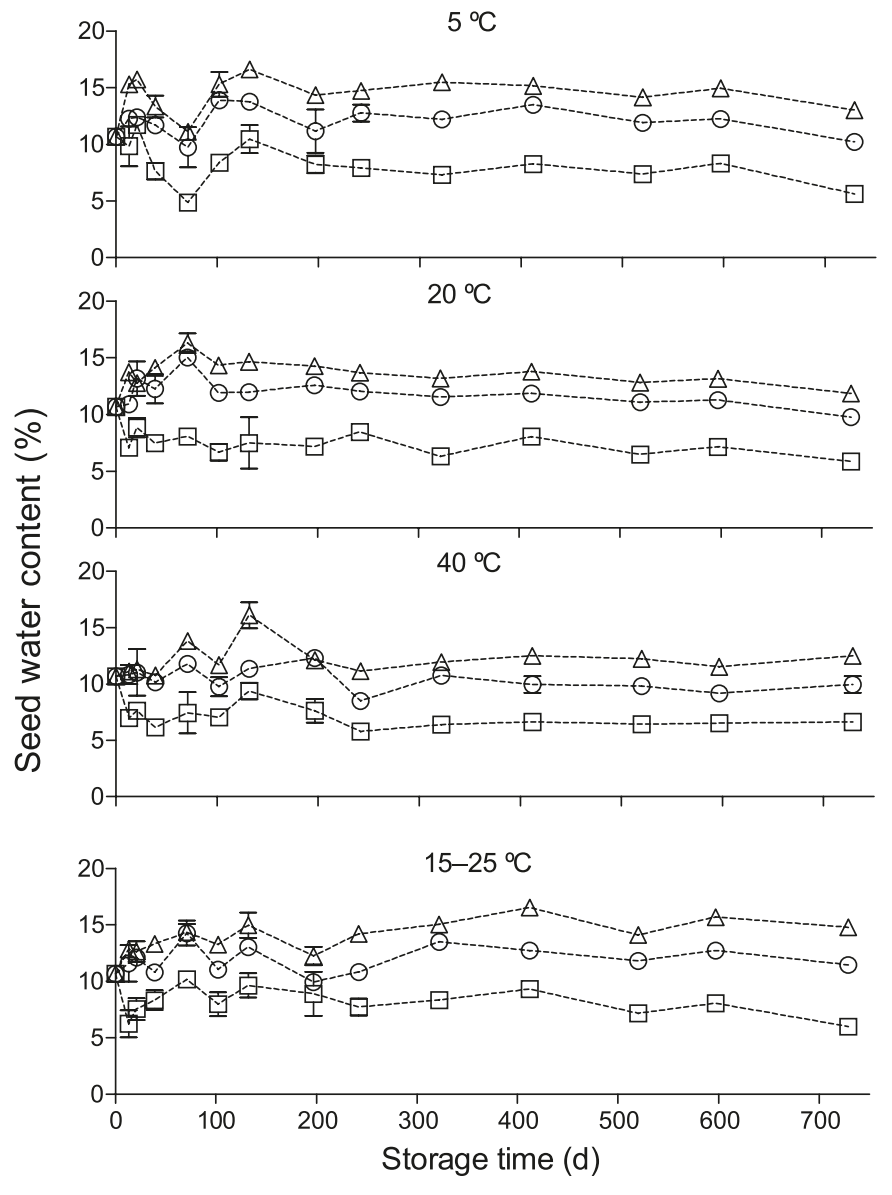

point, seedling trays were placed in a greenhouse at a nominal temperature of $15{ }^{\circ} \mathrm{C}$ (night) $-25{ }^{\circ} \mathrm{C}$ (day), with natural photoperiod. The presence of endophyte hyphae in L. multiflorum was assessed in the first 1-2 $\mathrm{mm}$ of the leaf sheath (see Christensen et al. 2002). Epidermal pieces peeled from the base of the leaf sheath of 3-4 leaves seedlings were stained with alkaline Rose Bengal stain (see Bacon and White 1994) and examined for the presence of endophyte mycelium by the method of Belanger (1996), with minor modifications. After approximately $10 \mathrm{~min}$, endophyte hyphae were searched for using light microscopy. The morphology of Neotyphodium endophyte hyphae infecting L. multiflorum has been well described, presenting a pattern of convoluted and bunched, infrequently branched mycelium (Moon et al. 2000; Christensen et al. 2002; Sugawara et al. 2006). Thus, the conspicuous pattern of growth of the endophyte Neotyphodium occultans can easily be distinguished from other endophytic fungal hyphae, and mistakes are highly unlikely in positively identifying the endophyte. The detection of endophyte hyphae in these seedlings is evidence of viability in seed. Endophyte viability estimated at the beginning of the experiment (day 0) represents the maximum viability. 
Fig. 2. Proportion of viable Lolium multiflorum seeds for the E+ $(\mathbf{O})$ and E- $(\bigcirc)$ biotypes along 729 d of storage. Seeds were stored under 12 different conditions resulting from the combination of three nominal relative humilities (5\%, 43\%, and $75 \%)$ and four temperatures (5, 20,40 , and $15-25^{\circ} \mathrm{C}$ ). Each point was obtained from the evaluation of each one of 60 seeds and a logistic curve was fitted in each graph for E+ (continuous lines) and for E- (broken lines) separately (see Statistical analyses). There were not enough E- seeds to estimate the viability in some treatments at the last extraction time.

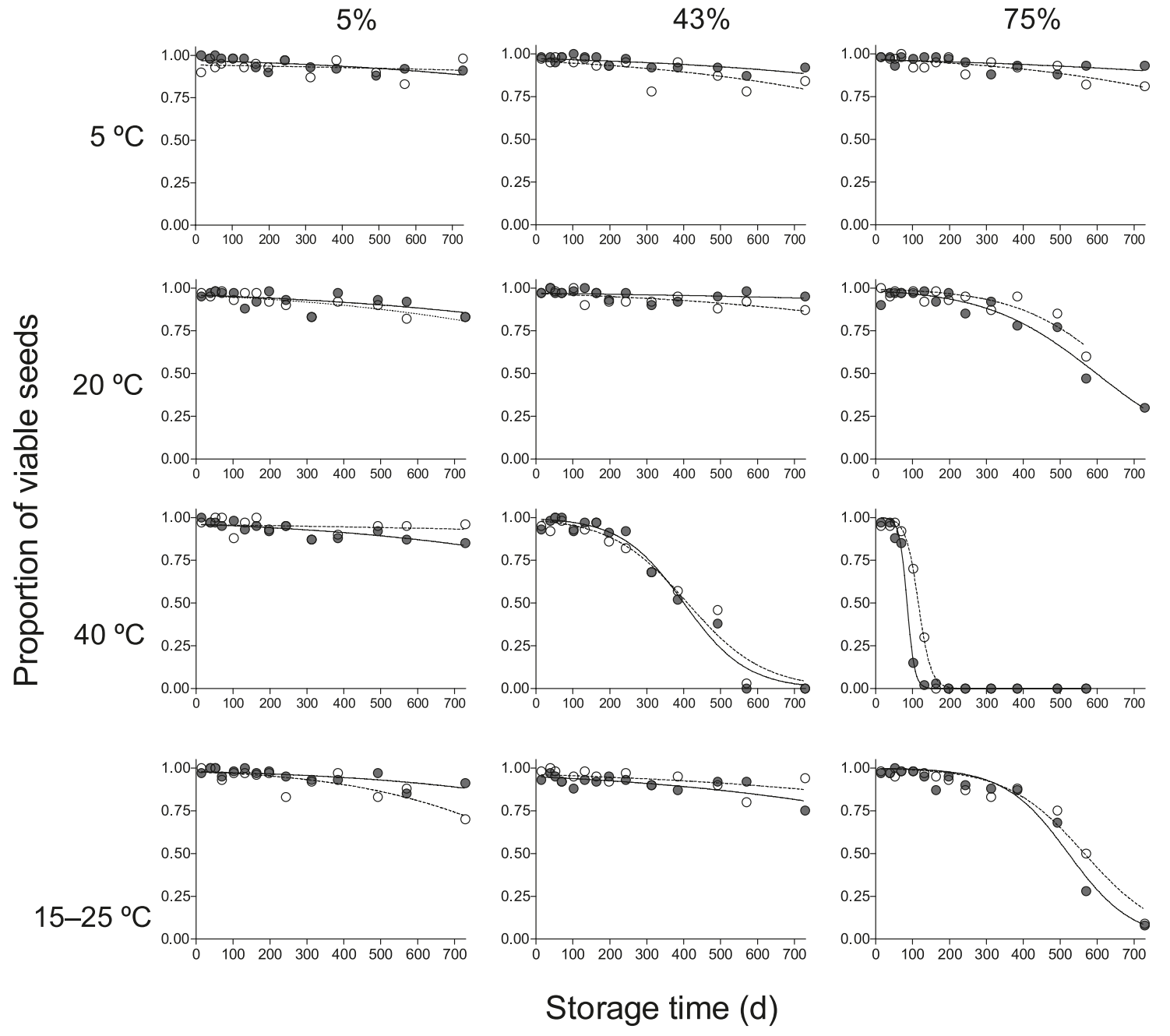

\section{Seed water content at equilibrium}

Seed water content achieved by the E+ and the E- biotype seed lots was recorded at 12, 36, and $128 \mathrm{~d}$ from the beginning of the experiment. On each date, three samples of 30 seeds per biotype were randomly selected from each box and seed water content was estimated as described above.

\section{Statistical analyses}

The proportion of viable seeds and the proportion of seeds with viable endophyte were strictly bounded, showing nonconstant variance, and errors were not normally distributed. Thus, minimum adequate models were estimated under Generalized Linear Models (Statistical Software R) using binomial error distribution and logit link (that assumes a logistic function between viability and time for example, see Figs. 2 and 3). The individual probability of viable seed or endophyte (viable $=1$ and nonviable $=0$ ) was modeled as a function of biotype (E+ and $\mathrm{E}-$, only for seeds), temperature (four levels), relative humidity (three levels), time (14 extraction dates), and their interactions. Therefore, the null model had 336 residual degrees of freedom for seed viability and 168 for endophyte viability. Overdispersion was corrected by increasing the expected variance using a dispersion parameter (the residual deviance divided by its degrees of freedom). Significance was tested by analysis of deviance ( $F$ test). It must be noted that our design had no true replicates for testing the effects of temperature (i.e., one chamber for each of the four temperature treatments), had four replicates for the effects of humidity (i.e., four boxes for each of the three relative humidity treatments), and no replicates for the temperature $\times$ humidity interaction. True replication is difficult to obtain, owing to the high logistic effort that these experiments demand (see Morrison and Morris 2000). We further believe that our long (729 d) evaluation of seeds and endophytes in each one of the 12 storage conditions is solid evidence with which to biologically infer the effects of endophyte infection on L. multiflorum seed viability and the differential in survival of endophyte mycelium: our two main objectives.

Endophyte effects on seed water content were analyzed by ANOVA using a General Linear Model (Statistical Software R). Models tested the effects of biotype (E+ or E-), 
Fig. 3. Proportion of Lolium multiflorum seeds with viable Neotyphodium endophyte along $729 \mathrm{~d}$ of storage. Seeds were stored under 12 different conditions resulting from the combination of three nominal relative humilities $(5 \%, 43 \%$, and $75 \%)$ and four temperatures (5, 20, 40 , and $15-25^{\circ} \mathrm{C}$ ). Each point was obtained from the evaluation of endophyte on viable seeds from the E+ biotype and logistic curve was fitted in each graph (see Statistical analyses).

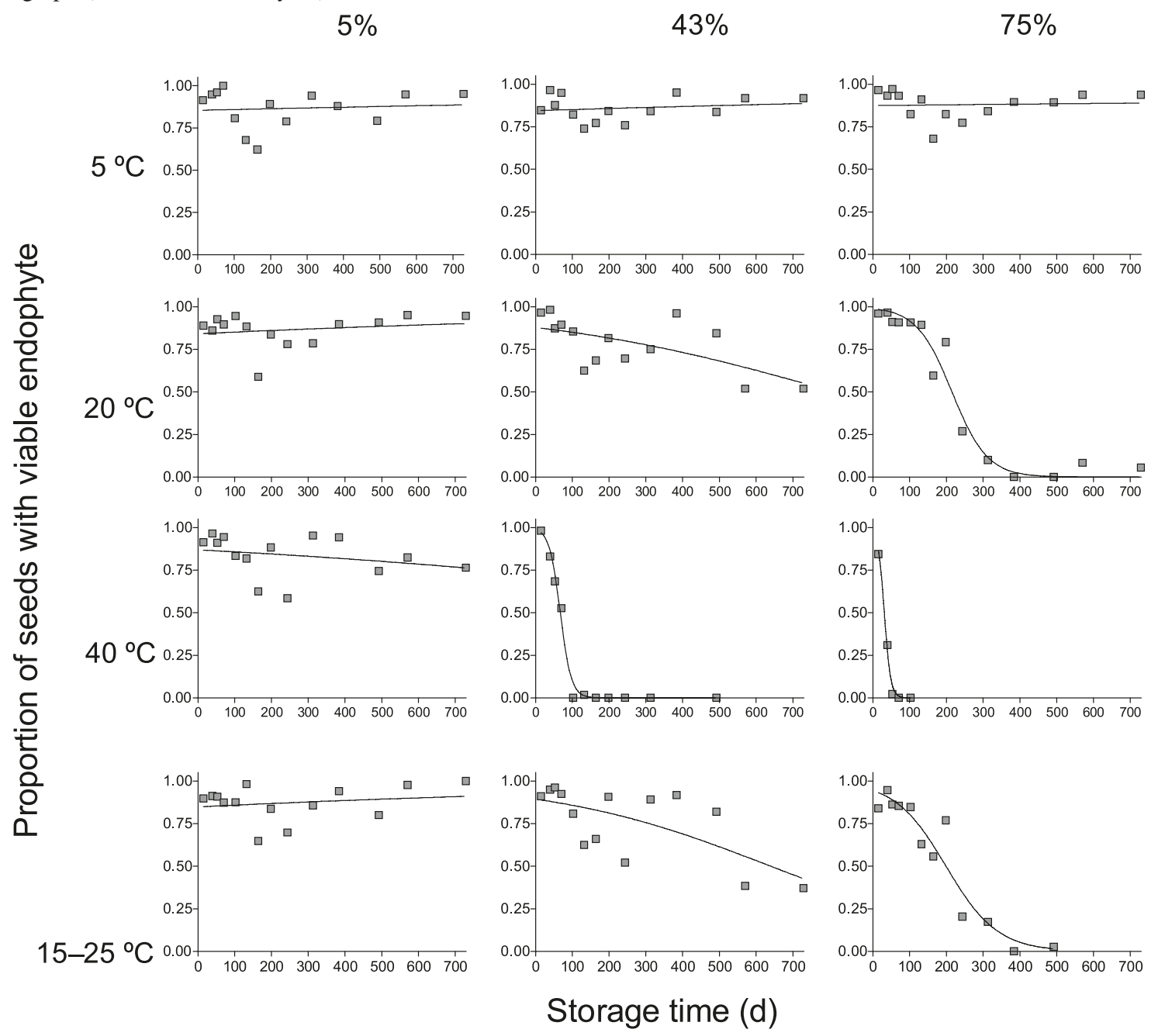

Table 1. Analysis of Deviance ( $F$ test) for the minimum adequate model that describes the effects of endophyte infection, temperature, and relative humidity $(\mathrm{RH})$ on the seed viability along $729 \mathrm{~d}$.

\begin{tabular}{llrr}
\hline Source & df & \multicolumn{1}{l}{$F$} & \multicolumn{1}{c}{$P$} \\
\hline Endophyte & 1 & 1.20 & 0.2743 \\
Time & 1 & 315.43 & $<0.0001$ \\
RH & 1 & 285.26 & $<0.0001$ \\
Temperature & 3 & 180.80 & $<0.0001$ \\
Endophyte $\times$ RH & 1 & 4.08 & 0.0442 \\
Time $\times$ RH & 1 & 15.60 & $<0.0001$ \\
Endophyte $\times$ temperature & 3 & 3.36 & 0.0190 \\
Time $\times$ temperature & 3 & 14.62 & $<0.0001$ \\
RH $\times$ temperature & 3 & 94.85 & $<0.0001$ \\
Time $\times$ RH $\times$ temperature & 3 & 11.89 & $<0.0001$ \\
\hline
\end{tabular}

temperature $\left(5,20,40\right.$, and $\left.15-25{ }^{\circ} \mathrm{C}\right)$, relative humidity $(5 \%, 43 \%$, and $75 \%)$, time $(12,36$, and $128 \mathrm{~d})$ and their interactions. The assumptions of ANOVA were accomplished without data transformation.

\section{Results}

Temperature and relative humidity interactions affected seed viability (Table 1; Fig. 2). The reduction in viability at higher temperatures was larger at higher relative humidity, and temperature had no significant impact on seed viability at a relative humidity of $5 \%$. Relative humidity had no effect on seed viability at a temperature of $5{ }^{\circ} \mathrm{C}$. The alternating temperature treatment $\left(15-25^{\circ} \mathrm{C}\right)$ affected seed viability in a similar way as the $20{ }^{\circ} \mathrm{C}$ (Fig. 2). Endophyte presence also affected seed viability, and this effect was strongly depended on relative humidity and temperature during seed storage (Table 1; Fig. 2). The endophyte reduced the viability of the seeds at high temperature or high relative humidity, but did not affect seed viability at lower temperature or relative humidity.

Temperature and relative humidity interactions affected endophyte viability in a similar direction as it affected seed viability (Table 2; Fig. 3). However, the decrease in viability was faster for the endophytes than for the seeds (Figs. 2 and 3 ). As observed for seed viability, the alternating temperature treatment $\left(15-25^{\circ} \mathrm{C}\right)$ had a similar effect on the endo- 
Fig. 4. Seed water content (\%) of Lolium multiflorum seeds for E+ ( $)$ and E- ( $\bigcirc)$ biotypes recorded at 12, 36, and 128 d of storage. Seeds were stored under 12 different conditions resulting from the combination of three nominal relative humilities $(5 \%$, 43\%, and $75 \%)$ and four temperatures $\left(5,20,40\right.$, and $\left.15-25^{\circ} \mathrm{C}\right)$. Symbols are means and bars are SEs $(n=3$, each sample comprised 30 seeds).

$5 \%$

$5^{\circ} \mathrm{C}$

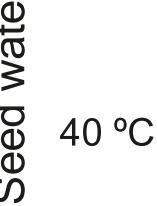
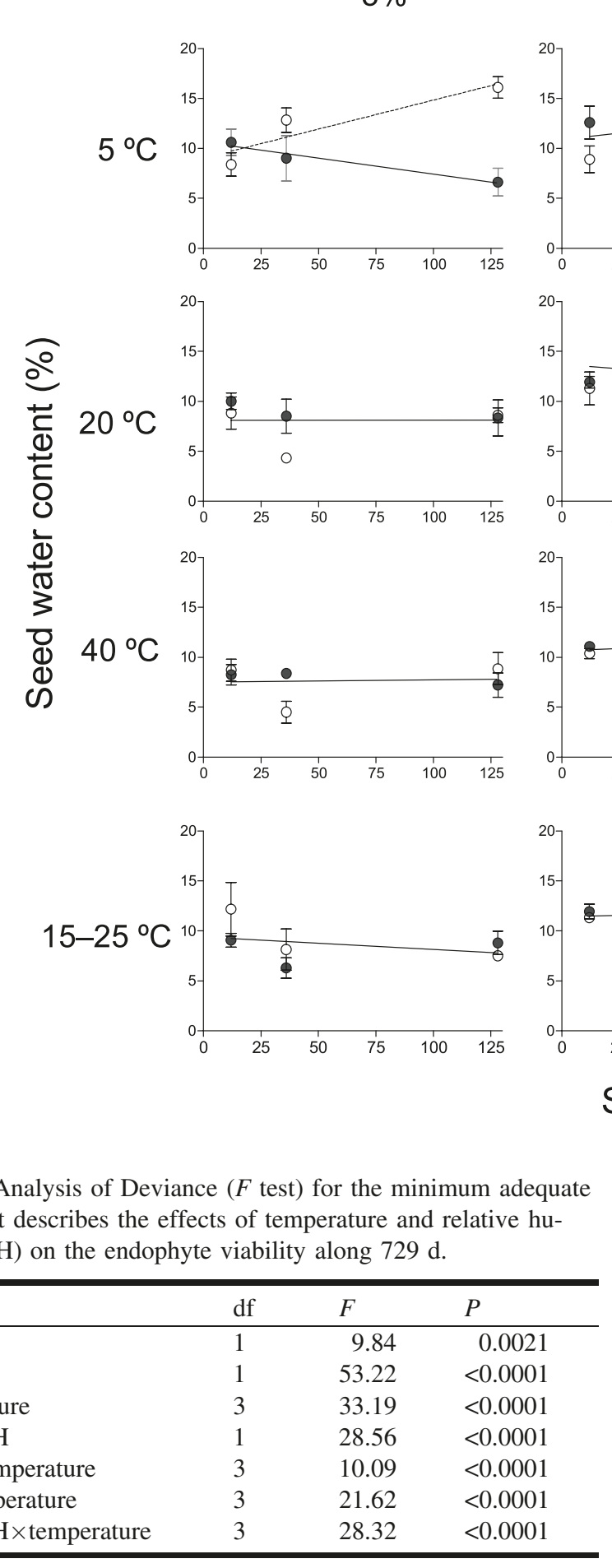

Table 2. Analysis of Deviance ( $F$ test) for the minimum adequate model that describes the effects of temperature and relative humidity $(\mathrm{RH})$ on the endophyte viability along $729 \mathrm{~d}$.

\begin{tabular}{llrr}
\hline Source & df & \multicolumn{1}{l}{$F$} & \multicolumn{1}{l}{$P$} \\
\hline Time & 1 & 9.84 & 0.0021 \\
RH & 1 & 53.22 & $<0.0001$ \\
Temperature & 3 & 33.19 & $<0.0001$ \\
Time $\times$ RH & 1 & 28.56 & $<0.0001$ \\
Time $\times$ temperature & 3 & 10.09 & $<0.0001$ \\
HR $\times$ temperature & 3 & 21.62 & $<0.0001$ \\
Time $\times$ RH $\times$ temperature & 3 & 28.32 & $<0.0001$ \\
\hline
\end{tabular}

phyte viability dynamics to the $20{ }^{\circ} \mathrm{C}$ temperature treatment at all relative humidity conditions (Fig. 3).

Endophyte effects on seed water content varied by temperature, $\mathrm{RH}$, and date $(P=0.045)$. Endophyte presence modified seed water content after $128 \mathrm{~d}$ of storage at $5{ }^{\circ} \mathrm{C}$
$43 \%$

$75 \%$
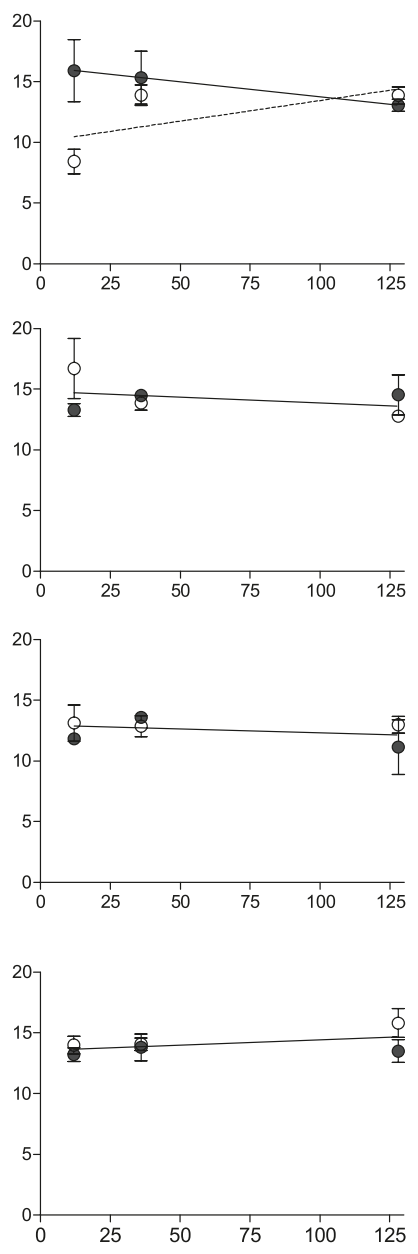

Storage time (d)

and 5\% RH, and after $12 \mathrm{~d}$ at $5{ }^{\circ} \mathrm{C}$ with $75 \%$ relative humidity (Fig. 4).

\section{Discussion}

This study provides an insight to the environmental regulation of an endophytic fungus and the viability of its host seeds. We showed that both the effect of endophyte on seed viability and the differential viability of endophytes and their host seeds occur only under certain temperature and humidity conditions, and were not mediated by differential seed water content. According to our results, when afterripening environmental conditions are unfavorable, the fungus viability is dramatically reduced and its presence may affect seed viability. Noteworthy when the maximum differences in viability between the infected and noninfected seeds occurred $\left(40{ }^{\circ} \mathrm{C}\right.$ with $75 \%$ relative humidity), seedlings derived from the infected seeds were free of the endophyte, suggesting that the population had lost its ability to transmit the fungus to the plant. Overall, changes in the 
endophyte infection frequency of the tested seed populations were produced mainly by endophyte death that occurred long before host-seed death, and secondly by the differential death of endophyte-infected and noninfected seeds. These findings are important, since hazardous environmental conditions similar to the ones we tested, are frequently found in nature and they alter the viable-endophyte infection frequency of seed through time, which in turn impacts on the future performance of the population (Clay and Schardl 2002).

The temporal dynamics of seed and endophyte viability matched the pattern previously described for $F$. arundinacea and for L. perenne (Rolston et al. 1986; Welty et al. 1987; Wheatley et al. 2007). At low seed water content and temperature, seed and endophyte survival remained high throughout the whole experiment. It has been previously suggested that the high temperature sensitivity of endophytes increases under high RH (Latch and Christensen 1982; Siegel et al. 1984; Rolston et al. 1986; Welty et al. 1987). Accordingly, viability loss in both seed and endophyte was faster under the highest temperatures and $\mathrm{RH}$, with a relatively greater impact on the endophyte than on the seed. The highest differences between seed viability of E+ and E- biotypes also occurred under the same extreme conditions.

In a previous study we found that after $6 \mathrm{~h}$ exposure to a vapour-saturated atmosphere, endophyte-infected seeds reached higher water contents than noninfected. Based on these results, we suggested that seed and endophyte viability may be regulated by means of the capacity of hyphae to change the water relations inside the seeds (Gundel et al. 2007). Endophyte hyphae could be affecting not only the rate of seed imbibition (at higher relative humidity) and the rate of seed dehydration (at lower relative humidity), but also the seed water content at equilibrium. Here, changes in seed water content due to the endophyte infection were not related with the observed patterns of seed and endophyte viability. In fact, where the highest negative endophyte impact on seed viability appeared $\left(40{ }^{\circ} \mathrm{C}\right.$ with $\left.75 \% \mathrm{RH}\right)$ there was no detectable differences in seed water content. Further, changes in seed water content due to the infection, were only detected in those treatments where neither seed viability nor endophyte viability were affected $\left(5{ }^{\circ} \mathrm{C}\right.$ with $5 \%$ and $75 \% \mathrm{RH})$. As an alternative hypothesis, we propose that endophyte hyphae could be affecting the distribution of water within the seed without producing any detectable difference in seed water content at equilibrium. Likewise, the effect of endophyte presence on seed water relations and hence on seed survival might depend on the hyphae concentration, which varies with growth conditions and host genotypes (Spiering et al. 2006; Rasmussen et al. 2007). Future experiments are needed to elucidate these mechanisms.

The experimental set-up used in this study allowed for the identification of processes accounting for variations in endophyte infection frequency in seed populations, and to weigh their relative importance. The endophyte infection frequency in grass populations has always been attributed to differential fitness between infected and noninfected related plants (Clay and Schardl 2002; Faeth and Sullivan 2003). However, in recent years, researchers acknowledged that endophytes and hosts have different sensitivities to environmental factors (Hill et al. 2005; Rasmussen et al. 2007).
These different requirements are likely to produce variations in the endophyte vertical transmission efficiency (Hill et al. 2005), which under natural conditions would affect the final endophyte infection frequency in grass populations (Ravel et al. 1997; Clay and Schardl 2002). The dynamics of endophyte survival reported in our study supports the hypothesis that changes in endophyte infection frequency in seed populations may be determined by a low survival of the fungus. If the endophyte dies before its host seed, frequency of endophyte infection will be mainly determined by transmission efficiency, rather than differential fitness between endophyte infected and noninfected seeds. Reduction in vertical transmission due to fungus mortality and E+ seeds mortality should be important in ecosystems with periods of high water content in soil and high temperature (Hume and Barker 2005).

Studies under controlled environments may provide valuable information on the physiological mechanisms interacting between symbionts in the grass-endophyte mutualism. Nonetheless, these results could be very different from those obtained in natural systems. In nature, failures in the endophyte vertical transmission should be compensated by the relative fitness of $\mathrm{E}+$ plants over $\mathrm{E}-$ plants, to maintain high frequencies of endophyte infection. Differences in relative fitness between both biotypes may be driven by both abiotic and abiotic factors (Clay and Schardl 2002). We have found that endophyte-infected L. multiflorum seeds displayed higher dormancy level than endophyte-free seeds (Gundel et al. 2006a, 2006b). Despite the fact that increased seed dormancy could potentially reduce the ability of endophyte to survive (Clay and Schardl 2002) it is a riskavoiding trait that would improve seed fitness and so overall survival of the endophyte (Martínez-Ghersa et al. 2000). Additionally, it has been shown that endophyte infection can deter predators from eating seeds (Madej and Clay 1991; Popay et al. 2000). The ecological conditions found by the seeds may show large variation and may depend on landscape characteristics and land use. For example, in agricultural systems the seeds may be buried by tillage to a soil depth where both daily mean temperature and temperature fluctuation decreases. According to our results, if the seeds are stored in the soil for long periods, failures in endophyte transmission would be expected. In these ecological conditions, nongerminating seeds could remain alive while endophyte mortality would increase. Conversely in grasslands, where seed are placed at the soil surface, the ability of seed to germinate in a safe site and deterrence to herbivory are adaptive traits driven by the endophyte (Madej and Clay 1991; Popay et al. 2000; Clay and Schardl 2002; Gundel et al. 2006a, 2006b). In such systems, higher fitness of infected seeds would overcompensate any failure in endophyte vertical transmission.

\section{Acknowledgements}

The authors thank M. Colabelli and A. Peretti for their technical assistance. The author P.E.G. especially thanks M. Gundel for technical support during the whole experiment. This work was financially supported by a grant from University of Buenos Aires (UBACYT G042). The authors P.E.G. and L.A.G. hold a fellowship from Consejo Nacional de Investigaciones Cientificas y Tecnológicas (Argentina). 


\section{References}

Bacon, C.W., and White, J.F., Jr. 1994. Stains, media, and procedures for analyzing endophytes. In Biotechnology of endophytic fungi of grasses. Edited by C.W. Bacon and J.F. White, Jr. CRC Press, Inc. Boca Raton, Fla. pp. 47-56.

Belanger, F.C. 1996. A rapid seedling screening method for determination of fungal endophyte viability. Crop Sci. 36: 460-462.

Christensen, M.J., Bennett, R.J., and Schmid, J. 2002. Growth of Epichloë/Neotyphodium and p-endophytes in leaves of Lolium and Festuca grasses. Mycol. Res. 106(1): 93-106. doi:10.1017/ S095375620100510X.

Clay, K., and Schardl, C. 2002. Evolutionary origin and ecological consequences of endophyte symbiosis with grasses. Am. Nat. 160(S4): S99-S127. doi:10.1086/342161.

Ellis, R.H., and Hong, T.D. 2006. Temperature sensitivity of the low-moisture-content limit to negative seed longevity - moisture content relationships in hermetic storage. Ann. Bot. (Lond.), 97: 785-791. doi:10.1093/aob/mcl035. PMID:16495314.

Ellis, R.H., and Roberts, E.H. 1980. Improved equations for the prediction of seed longevity. Ann. Bot. (Lond.), 45: 13-30.

Faeth, S.H., and Sullivan, T.J. 2003. Mutualistic asexual endophytes in a native grass are usually parasitic. Am. Nat. 161: 310-325. doi:10.1086/345937. PMID:12675375.

Gundel, P.E., Maseda, P.H., Vila-Aiub, M.M., Ghersa, C.M., and Benech-Arnold, R.L. 2006a. Neotyphodium fungi effects on Lolium multiflorum seed germination in relation to water availability. Ann. Bot. (Lond.), 97: 571-577. doi:10.1093/aob/mcl004. PMID:16446287.

Gundel, P.E., Maseda, P.H., Ghersa, C.M., and Benech-Arnold, R.L. 2006b. Neotyphodium endophyte effects on dormancy and germination rate of Lolium multiflorum seeds. Austral Ecol. 31: 767-775. doi:10.1111/j.1442-9993.2006.01638.x.

Gundel, P.E., Landesmann, J.B., Martínez-Ghersa, M.A., and Ghersa, C.M. 2007. Effects of Neotyphodium endophyte infection on seed viability and germination vigor in Lolium multiflorum under accelerated ageing condition. In Proceedings of The 6th International Symposium on Fungal Endophytes of Grasses, "From Lab to Farm", Grassland Research and Practice Series No. 13. Edited by A.J. Popay and E.R. Thom. New Zealand Grassland Association (Inc.), Christchurch, New Zealand. pp. 277-280.

Hill, N.S., Bouton, J.H., Hiatt, E.E., III, and Kittle, B. 2005. Seed maturity, germination, and endophyte relationships in tall fescue. Crop Sci. 45: 859-863. doi:10.2135/cropsci2004.0057.

Holder, T.L., West, C.P., Turner, K.E., McConnell, M.E., and Piper, E.L. 1994. Incidence and viability of Acremonium endophytes in tall fescue and meadow fescue plant introductions. Crop Sci. 34: 252-254.

Hume, D.E., and Barker, D.J. 2005. Growth and management of endophytic grasses in pastoral agriculture. In Neotyphodium in cool-season grasses. Edited by C. Roberts, C.P. West, and D. Spiers. Blackwell publishing, Ames, Iowa. pp. 201-226.

Hung, L.Q., Hong, T.D., and Ellis, R.H. 2001. Constant, fluctuating and effective temperature and seed longevity: a tomato (Lycopersicon esculentum Mill.) exemplar. Ann. Bot. (Lond.), 88: 465-470. doi:10.1006/anbo.2001.1487.

International rules for seed testing. 1996. Seed Science and Technology 27, Supplement: Rules. International Seed Testing Association, Zurich, Switzerland.

Latch, G.C.M., and Christensen, M.J. 1982. Ryegrass endophyte, incidence, and control. N Z J. Agric. Res. 25: 443-448.

Madej, C.W., and Clay, K. 1991. Avian seed preference and weight loss experiments: the effect of fungal endophyte-infected tall fescue seeds. Oecologia (Berl.), 88: 296-302. doi:10.1007/ BF00320825.
Majewska-Sawka, A., and Nakashima, H. 2004. Endophyte transmission via seeds of Lolium perenne L.: inmunodetection of fungal antigens. Fungal Genet. Biol. 41: 534-541. doi:10.1016/j. fgb.2004.01.005. PMID:15050542.

Martínez-Ghersa, M.A., Ghersa, C.M., Benech-Arnold, R.L., MacDonough, R.M., and Sanchez, R.A. 2000. Adaptive traits regulating dormancy and germination of invasive species. Plant Species Biol. 15(2): 127-137. doi:10.1046/j.1442-1984.2000. 00033.x.

Medvescigh, J., Maidana, R., De Battista, J.P., and Costa, M. 2004. Annual ryegrass endophyte viability evolution under storage conditions. A note. In Technology Transfer and Quality Assurance. 5th Neotyphodium Symposium. Edited by R. Kallenbach, C. Rosenkrans, and T.R. Lock. Fayetteville, Ark. p. 514.

Merritt, D.J., Touchell, D.H., Senaratna, T., Dixon, K.W., and Sivasithamparam, K. 2003. Water sorption characteristics of seeds of four Western Australian species. Aust. J. Bot. 51: 85-92. doi:10.1071/BT02040.

Moon, C.D., Scott, B., Schardl, C.L., and Christensen, M.J. 2000. The evolutionary origins of Epichlö̈ endophytes from annual ryegrasses. Mycologia, 92: 1103-1118. doi:10.2307/3761478.

Morrison, D.A., and Morris, E.C. 2000. Pseudoreplication in experimental designs for the manipulation of seed germination treatments. Austral Ecol. 25(3): 292-296.

Philipson, M.N., and Christey, M.C. 1986. The relationship of host and endophyte during flowering, seed formation, and germination of Lolium perenne. N.Z. J. Bot. 24: 125-134.

Popay, A., Marshall, S., and Baltus, J. 2000. Endophyte infection influence disappearance on perennial ryegrass seed. N Z Plant Prot. 53: 398-405.

Rasmussen, S., Parsons, A.J., Bassett, S., Christensen, M.J., Hume, D.E., Johnson, L.J., Johnson, R.D., Simpson, W.R., Stacke, C., Voisey, C.R., Xue, H., and Newman, J.A. 2007. High nitrogen supply and carbohydrate content reduce fungal endophyte and alkaloid concentration in Lolium Perenne. New Phytol. 173: 787-797. doi:10.1111/j.1469-8137.2006.01960.x. PMID:17286827.

Ravel, C., Michalakis, Y., and Charmet, G. 1997. The effect of imperfect transmission on the frequency of mutualistic seed-borne endophytes in natural populations of grasses. Oikos, 80: 18-24. doi:10.2307/3546511.

Rolston, M.P., Hare, M.D., Moore, K.K., and Christensen, M.J. 1986. Viability of Lolium endophyte fungus in seed stored at different seed moisture contents and temperature. N Z J. Exp. Agric. 14: 297-300.

Siegel, M.R., Johnson, M.C., Varney, D.R., Nesmith, W.C., Buckner, R.C., Bush, L.P., Burrus, P.B., II, Jones, T.A., and Boling, J.A. 1984. A fungal endophyte in tall fescue: Incidence and dissemination. Phytopathology, 74(8): 932-937.

Spiering, M.J., Greer, D.H., and Schmid, J. 2006. Effects of the fungal endophyte, Neotyphodium lolii, on net photosynthesis and growth rates of Perennial Ryegrass (Lolium perenne) are independent of In Planta endophyte concentration. Ann. Bot. (Lond.), 98: 379-387. doi:10.1093/aob/mcl108. PMID:16735403.

Sugawara, K., Inoue, T., Yamashita, M., and Ohkubo, H. 2006. Distribution of the endophytic fungus, Neotyphodium occultans in naturalized Italian ryegrass in western Japan and its production of bioactive alkaloids known to repel insect pests. Grassl. Sci. 52: 147-154. doi:10.1111/j.1744-697X.2006.00060.x.

Vertucci, C.W., and Ross, E.E. 1990. Theoretical basis of protocols for seed storage. Plant Physiol. 94: 1019-1023. PMID:16667791.

Walters, C.S., and Hill, L.M. 1998. Water sorption isotherms of seeds from ultradry experiments. Seed Sci. Res. 8(1): 69-73. 
Welty, R.E., Azevedo, M.D., and Cooper, T.M. 1987. Influence of moisture content, temperature, and length of storage on seed germination and survival of endophytic fungi in seeds of tall fescue and perennial ryegrass. Phytopathology, 77: 893-900. doi:10.1094/Phyto-77-893.

Welty, R.E., Craig, A.M., and Azevedo, M.D. 1994. Variability of ergovaline in seeds and straw and endophyte infection in seeds among endophyte-infected genotypes of tall fescue. Plant Dis. 78(9): 845-849.

Wheatley, W.M., Kemp, H.W., Simpson, W.R., Hume, D.E., Nicol, H.I., Kemp, D.R., and Launders, T.E. 2007. Viability of endemic endophyte (Neotyphodium lolii) and perennial ryegrass (Lolium perenne) seed at retail and wholesale outlets in southeastern Australia. Seed Sci. Technol. 35: 360-370. 


\section{This article has been cited by:}

1. Kari Saikkonen, Kalle Ruokolainen, Otso Huitu, Pedro E. Gundel, Tiina Piltti, Cyd E. Hamilton, Marjo Helander. 2013. Fungal endophytes help prevent weed invasions. Agriculture, Ecosystems \& Environment 165, 1-5. [CrossRef]

2. P. Tian, T.-N. Le, K. F. Smith, J. W. Forster, K. M. Guthridge, G. C. Spangenberg. 2013. Stability and viability of novel perennial ryegrass host?Neotyphodium endophyte associations. Crop and Pasture Science 64:1, 39. [CrossRef]

3. Pedro E. Gundel, Cyd E. Hamilton, Charlotte E. Seal, Marjo Helander, María Alejandra Martínez-Ghersa, Claudio M. Ghersa, Beatriz R. Vázquez de Aldana, Iñigo Zabalgogeazcoa, Kari Saikkonen. 2012. Antioxidants in Festuca rubra L. seeds affected by the fungal symbiont Epichloë festucae. Symbiosis 58:1-3, 73-80. [CrossRef]

4. P. E. Gundel, J. A. Rudgers, C. M. Ghersa. 2011. Incorporating the process of vertical transmission into understanding of hostsymbiont dynamics. Oikos 120:8, 1121-1128. [CrossRef]

5. P. E. Gundel, I. Zabalgogeazcoa, B. R. Vázquez de Aldana. 2011. Interaction between plant genotype and the symbiosis with Epichlo\# fungal endophytes in seeds of red fescue (Festuca rubra). Crop and Pasture Science 62:11, 1010. [CrossRef]

6. Masayuki Yamashita, Miyuki Iwamoto, Keisuke Maruyama, Minoru Ichihara, Hitoshi Sawada. 2010. Contrasting infection frequencies of Neotyphodium endophyte in naturalized Italian ryegrass populations in Japanese farmlands. Grassland Science 56:2, 71-76. [CrossRef] 